J. Jpn. Soc. Comp. Statist., 9(1996), 31-51

\title{
NONPARAMETRIC ESTIMATION AND NUMERICAL EVALUATION OF TIME POINT OF OCCURRENCE OF EVOKED POTENTIAL IN MAGNETOENCEPHALOGRAM
}

\author{
Isao Hemmi *
}

\begin{abstract}
In order to investigate the rate of transferring information from the sensory organ to the brain hemisphere through the averaged magnetoencephalogram (MEG) data, we propose an estimator of the time point at which cerebral evoked potential (CEP) occurs. We regard the averaged MEG as a stationary process before the occurrence of the CEP and as a nonstationary process with a mean function, whose functional form is unknown, after the occurrence of the CEP. We approximate the mean function in a neighborhood of the time point of the occurrence by a linear function. We propose an estimator of the time point of the occurrence, that is, the first time point at which the slope of a linear function becomes nonzero. We compare, by simulation studies, the proposed estimator with some other estimators. We find that our estimator is reasonable when the mean value gradually changes. Finally, we show an example of application of the proposed method to real MEG data.
\end{abstract}

\section{Introduction}

In neuroscience, especially neurophysiology, cognitive science and clinical neurology, it is interesting to study cerebral evoked potential (CEP), which is the response of the brain to stimuli as electromagnetic potential. In particular, for investigating the rate of transferring information from the sensory organ to the brain hemisphere, we would examine a time lag between the stimulation and appearance of the CEP. In order to observe the brain activity, magnetoencephalogram (MEG) is a useful noninvasive method and we record the brain activity as time series of MEG. Since the CEP is much lower in amplitude than the potential of ongoing background activity, physiologists usually estimate the CEP by repeating stimulation and averaging the potential records that are time-locked to the stimuli (Glaser and Ruchkin, 1976). Then, from a plot of the averaged MEG they detect, by eye, the time point at which the CEP appears. Thus, a statistical method is necessary to estimate the time point at which the CEP occurs from the averaged MEG. From now on, the time point of the occurrence of the CEP will be described as the change-point.

For analysis we treat the averaged MEG as a time series. From the physiological findings that the electromagnetic potential of background activity can be regarded as a stationary process and the CEP as a deterministic function (Glaser and Ruchkin, 1976), we regard the averaged MEG as a stationary process before the change-point and as a mean-varying

\footnotetext{
*Tokyo Metropolitan Institute for Neuroscience; 2-6 Musashidai, Fuchu, Tokyo 183, Japan; E-mail: hemmi@tmin.ac.jp

Key words: change-point; MEG; neuroscience; nonparametric inference; nonstationary time series; regression
} 
nonstationary process after the change-point. This nonstationary process is supposed to be the sum of a deterministic mean value function, which represents the CEP, and the same stationary process as the process before the change-point. If the functional form of the mean value function is known, the change-point could be estimated in the framework of two-phase regression (Quandt,1958; Hinkley, 1969; Kim and Siegmund, 1989; Lee, 1993). However, the functional form is not known. Hence, in this paper we take a nonparametric approach in the sense that the functional form of the mean value function is not assumed.

Concerning nonparametric estimation of a change-point, the following papers have been published. Müller (1992) proposed an estimator of the change-point at which a function or its derivatives are discontinuous by using a one-sided kernel when the error term is a sequence of independent and identically distributed (i.i.d.) random variables. Chu (1994) considered the case when the mean value function or its derivative is discontinuous at two time points and is constant before the first change-point and after the second change-point. The error term is assumed to be a sequence of i.i.d. random variables. He presented a nonparametric estimator of these two change-points. Müller's estimator is superior to Chu's in the sense of order of convergence as sample size increases, if the orders of derivatives that are discontinuous at the change-points are known (Chu, 1994). Besides, Scariano and Watkins (1988) showed nonparametric estimators of the change-point at which the slope of linear trend varies. Carlstein (1988) proposed a class of nonparametric estimators of the change-point at which distribution functions change. Consistency of his estimators was proved under very weak conditions by Carlstein and Lele (1994) when a random sequence is stationary and ergodic. However, it is not clear whether or not the above estimators are applicable to the averaged MEG, mainly because statistical properties of Müller's estimator and Scariano and Watkins's estimator have not been examined when the error term is stochastic, and because Carlstein's estimator does not take into account a situation where the distribution function continues varying after the change-point. Hence, an appropriate estimator of the change-point for the averaged MEG is required.

In this paper, we propose an estimator of the change-point by locally fitting a linear function of time to the averaged MEG in the right side of the change-point. We describe, in section 2 , the proposed method. In section 3 , we investigate the critical point for detecting the change-point. For examining goodness of the proposed method, we compare, in section 4, the proposed method with Müller's, Carlstein's, and Scariano and Watkins's methods by simulation studies for several mean value functions. Finally, to demonstrate an example of application of the proposed method, we analyze real MEG data in the case where the brain of human subject is stimulated by flash light.

\section{An estimator of the change-point by locally fitting a linear function}

Let us consider the following situation. We have samples of the averaged MEG, $Y_{1}, \ldots, Y_{T}$. The CEP occurs at an unknown time point $\tau_{0}$ such that $\tau_{0} \geq S$, where $\tau_{0}$ is the change-point to be estimated and $S$ is the time point at which the stimulus is presented to the sensory organ. Thus, by the physiological finding as stated in the previous section, $Y_{t}$ is written as

$$
Y_{t}= \begin{cases}\mu_{0}+u_{t} & t=1, \ldots, \tau_{0} \\ \mu_{0}+g(t)+u_{t} & t=\tau_{0}+1, \ldots, T\end{cases}
$$

where $u_{t}$ is a weakly stationary process with mean 0 and variance $\sigma^{2}, \mu_{0}$ is an unknown 
constant and $g(t)$ is an unknown deterministic function such that $g\left(\tau_{0}\right)=0$. Here $g(t)$ represents the CEP at a time point $t$.

We now describe our proposed method for estimating the change-point $\tau_{0}$ from $Y_{1}, \ldots, Y_{T}$.

We consider the case when the functional form of $g(t)$ is not known. Here we assume that $g(t)$ is analytic. Then we can expand $g(t)$ in a Taylor series

$$
g(t)=g\left(\tau_{0}\right)+\left(t-\tau_{0}\right) g^{\prime}\left(\tau_{0}\right)+\frac{\left(t-\tau_{0}\right)^{2}}{2} g^{\prime \prime}\left(\tau_{0}\right)+\cdots
$$

where $g^{\prime}(t)$ and $g^{\prime \prime}(t)$ are the first and second derivatives with respect to $t$, respectively. Hence, $g(t)$ can be approximated by

$$
g(t)=g\left(\tau_{0}\right)+\left(t-\tau_{0}\right) g^{\prime}\left(\tau_{0}\right)
$$

in a neighborhood of $\tau_{0}$. Because $\tau_{0}$ is unknown, we search for $\tau_{0}$ successively from $s_{1}$ to $s_{2}$, where $s_{1}$ and $s_{2}$ are given integers such that $S \leq s_{1} \leq s_{2} \leq T$.

First, for an integer $\tau \in\left[s_{1}, s_{2}\right]$, we suppose that $g(t)=0$ for $t \leq \tau$ and $g(t)$ can be approximated by a linear function of $t$ in $[\tau, \tau+L]$, and we fit

$$
\mu_{\tau}+(t-\tau) \beta_{\tau}
$$

to $\left\{Y_{t}\right\}$ in $[\tau, \tau+L]$, where $L$ is a small positive integer to be appropriately chosen. We obtain, by the least squares method, an estimator of $\beta_{\tau}$

$$
\hat{\beta}_{\tau}=\left(\sum_{x=1}^{L} x^{2}\right)^{-1} \sum_{x=1}^{L} x\left(Y_{\tau+x}-\hat{\mu}_{\tau}\right)
$$

where

$$
\hat{\mu}_{\tau}=\tau^{-1} \sum_{i=1}^{\tau} Y_{i}
$$

Second, since $\hat{\beta}_{\tau}$ corresponds to an estimator of $g^{\prime}(\tau)$, we determine, by observing the closeness of $\hat{\beta}_{\tau}$ to 0 , whether or not

$$
g^{\prime}(\tau)=0
$$

holds. Hence, if $\tau$ is the first time point such that $\left|\hat{\beta}_{\tau}\right|$ is greater than a certain critical point $Z$, we take this $\tau$ as our estimator, $\hat{\tau}$, of $\tau_{0}$, that is,

$$
\hat{\tau}=\min \left\{\tau:\left|\hat{\beta}_{\tau}\right|>Z, s_{1} \leq \tau \leq s_{2}\right\} .
$$

If there does not exist any $\tau$ such that $\left|\hat{\beta}_{\tau}\right|>Z$ in $\left[s_{1}, s_{2}\right]$, then we define $\hat{\tau}$ as $T$.

Next, we will demonstrate a method to determine whether or not $\beta_{\tau}$ is equal to 0 . By (2) we have

$$
E \hat{\beta}_{\tau}= \begin{cases}0 & \tau \leq \tau_{0}-L \\ \left(\sum_{x=1}^{L} x^{2}\right)^{-1} \sum_{x=\tau_{0}-\tau+1}^{L} x g(\tau+x) & \tau_{0}-L<\tau \leq \tau_{0} \\ \left(\sum_{x=1}^{L} x^{2}\right)^{-1} \sum_{x=1}^{L} x\left\{g(\tau+x)-\tau^{-1} \sum_{t=\tau_{0}+1}^{\tau} g(t)\right\} & \tau_{0}<\tau\end{cases}
$$


and

$$
\operatorname{Var}\left(\hat{\beta}_{\tau}\right)=\left(\sum_{x=1}^{L} x^{2}\right)^{-2} \sum_{i=\max \left\{1, \tau_{0}-\tau+1\right\}}^{L} \sum_{j=\max \left\{1, \tau_{0}-\tau+1\right\}}^{L} i j d_{i j},
$$

where

$$
d_{i j}=\gamma_{|i-j|}+\tau^{-1}\left\{\gamma_{0}+2 \sum_{h=1}^{\tau-1}(1-h / \tau) \gamma_{h}-\sum_{k=1}^{\tau}\left(\gamma_{\tau+i-k}+\gamma_{\tau+j-k}\right)\right\}
$$

and $\gamma_{h}$ is $E u_{t} u_{t+h}$. Let us introduce a statistic

$$
U_{\tau}=\hat{\beta}_{\tau} / \sqrt{\operatorname{Var}\left(\hat{\beta}_{\tau}\right)} .
$$

Instead of observing whether or not $\left|\hat{\beta}_{\tau}\right|$ is greater than $Z$, we will see whether or not $\left|U_{\tau}\right|$ is greater than a certain critical point $z$. Because $\left\{\gamma_{h}\right\}$ in (4) are not known, we replace these by their estimators $\left\{\hat{\gamma}_{h}\right\}$. Here, as $\left\{\hat{\gamma}_{h}\right\}$ we employ an estimator which is obtained by fitting the first-order autoregressive $(\operatorname{AR}(1))$ model to the residuals

$$
e_{t}=Y_{t}-\hat{\mu}_{S}, \quad 1 \leq t \leq S,
$$

even though $\left\{u_{t}\right\}$ is not necessarily an $\operatorname{AR}(1)$ process.

\section{Determination of the critical point}

In the previous section, we have introduced a statistic $U_{\tau}$ for testing the hypothesis $\beta_{\tau}=0$. Here, we will determine a critical point $z$ appropriate for estimating the changepoint for practical use. At first, by simulations we study the distribution of $U_{\tau}$ under the hypothesis $\beta_{\tau}=0$ in order to obtain quantiles of the distribution of $U_{\tau}$ corresponding to some significance levels for the two-sided test. Next, considering various functional forms of mean value function, we carry out simulation studies to examine which significance level gives a good estimate of the change-point in terms of mean square error.

Now, let us study the distribution of $U_{\tau}$. The distribution of $U_{\tau}$ may depend on $\left\{\gamma_{h} / \sigma^{2}\right\}$, $S$ and $L$, because $\hat{\beta}_{\tau}$ is obtained from an interval of length $L,\left\{\gamma_{h}\right\}$ in (4) is estimated from $S$ residuals, and $\operatorname{Var}\left(\hat{\beta}_{\tau}\right)$ is a function of $\left\{\gamma_{h}\right\}$. Nonetheless, from a practical point of view, we will choose a single value of $z$ regardless of $\left\{\gamma_{h} / \sigma^{2}\right\}, S$ and $L$. For this purpose we investigate the relationships between $\left\{\gamma_{h} / \sigma^{2}\right\}, S, L$ and the distribution of $U_{\tau}$.

Taking $\operatorname{AR}(1)$ processes as $\left\{u_{t}\right\}$, we study the relationship between $\left\{\gamma_{h} / \sigma^{2}\right\}$ and the distribution of $U_{\tau}$. $\hat{\gamma}_{h}$ 's for $h \geq 2$ are determined from $\hat{\gamma}_{1}$ because $\left\{u_{t}\right\}$ is regarded as an $\operatorname{AR}(1)$ process in the proposed method. Then, instead of taking into account all $\left\{\gamma_{h} / \sigma^{2}\right\}$, we consider only $\gamma_{1} / \sigma^{2}$, which is denoted by $R$. Afterward we will examine whether the proposed method works, in cases of stationary processes other than $\mathrm{AR}(1)$ processes, for estimating the change-point by the critical point which is determined on the basis of $\operatorname{AR}(1)$ processes. In this simulation study we generated 1000 replicates of $\operatorname{AR}(1)$ process with mean 0 and variance 1

$$
u_{t}=a_{1} u_{t-1}+\xi_{t}, \quad t=1, \ldots, 550
$$

for each of the regression coefficients $a_{1}$, where $\xi_{t}$ is an independent and identically distributed normal random variable with mean 0 and the variance to be appropriately chosen. 
Since the time series of MEG is positively autocorrelated, we focus on processes with positive autocorrelation coefficients to examine effects of $R$ on the distribution of $U_{\tau}$. Note that $R$ is equal to $a_{1}$. Thus, we took $a_{1}$ to be $0.0,0.1, \ldots, 0.9$.

For seeing the relationship between $S$ and the distribution of $U_{\tau}$, we used $S=$ $20,50,100$ and 200 to estimate $\left\{\gamma_{h}\right\}$. We employed three lengths of interval $L=5,10$ and 20 for approximating the mean value function by a linear function. For each combination of $(R, S, L)$ we obtained the distribution of $U_{\tau}$.

Here, we illustrate the results of the simulations about the $(1-p / 2)$-quantiles, $Q_{p / 2}$, of the distribution of $U_{\tau}$ corresponding to significance levels $p=0.05,0.01,0.005$ and 0.001 , which are widely used. Figure 1 shows plots of $Q_{0.025}, Q_{0.005}, Q_{0.0025}$ and $Q_{0.0005}$ against $R$. The $Q_{p / 2}$ 's increase with $R$. On the other hand, as $S$ increases, the $Q_{p / 2}$ 's decrease and seem to approach to the corresponding quantiles of the normal distribution with mean 0 and variance 1 . In addition, the $Q_{p / 2}$ 's for $L<20$ are not greater than those for $L=20$. Therefore, from Figure 1, it seems reasonable to take the critical point $z$ to be 2, 3, 3.5 and 4 in order to test the hypothesis $\beta_{\tau}=0$ roughly at significance levels $0.05,0.01,0.005$ and 0.001 , respectively, for any $L \leq 20$, any $S \geq 20$ and any $R \geq 0$. These critical points are based on the assumption that the stationary process $\left\{u_{t}\right\}$ is an $\operatorname{AR}(1)$ process. Thus, taking into account cases when $\left\{u_{t}\right\}$ is not an $\operatorname{AR}(1)$ process, we will discuss which significance level to choose below.

Next, considering various cases of mean value function, we will examine which critical point is appropriate for estimating the change-point in the sense that mean square error (MSE) is small. We take the mean value before the change-point $\tau_{0}$ to be 0 . As mean value functions after $\tau_{0}$, we consider the following seven cases:

Case 1. $g(t)=a\left(t-\tau_{0}\right) / 10, \quad a=0,1,2,3$.

Case 2. $g(t)=4 \sin \left\{2 \pi\left(t-\tau_{0}\right) / 90\right\}$.

Case 3. $g(t)=4 \sin \left\{2 \pi\left(t-\tau_{0}\right) / 12\right\}$.

Case 4. $g(t)=2-2 \cos \left\{2 \pi\left(t-\tau_{0}\right) / 100\right\}$.

Case 5. $g(t)=\sqrt{t-\tau_{0}} / \exp \left\{0.02\left(t-\tau_{0}\right)\right\}$.

Case 6. $g(t)=\left\{\begin{array}{cc}0 & t \leq \tau_{0} \\ 2 & t>\tau_{0}\end{array}\right.$.

Case 7. $g(t)=w_{t}$. Here $w_{t}$ denotes a sample path of random walk described as

$$
w_{t}=\sum_{i=\tau_{0}+1}^{t} \epsilon_{i},
$$

where $\epsilon_{i}$ is an independent and normally distributed random variable with mean 0 and variance 0.64. $g(t)$ is shown in Figure 2.

In order to investigate a case when the mean value function is a linear function, we consider Case 1. Note that the case for $a=0$ is one when there is no change-point. For examining a case where the mean value function can be approximated by a linear function, we study Case 2. To look into a case where a linear function approximates the mean value function 
in a narrower range than in Cases 1 and 2, we take Case 3 into consideration. To examine cases where the first derivative of the mean value function at the change-point are extreme, that is, zero and infinite, we study Cases 4 and 5 . Concerning a case where the mean value is not continuous at the change-point, we consider Case 6. Seeing a case where the mean value function cannot be represented by any analytic function, we study Case 7 .

As a stationary process $\left\{u_{t}\right\}$ we consider the white noise

$$
u_{t}=\xi_{t}
$$

and the $\operatorname{AR}(1)$ process

$$
u_{t}=0.75 u_{t-1}+\xi_{t} .
$$

For examining cases of stationary processes other than $\operatorname{AR}(1)$ processes, we consider the first-order moving average $(\mathrm{MA}(1))$ process

$$
u_{t}=0.9 \xi_{t-1}+\xi_{t}
$$

and AR processes of higher orders. Since our concern is to analyze the MEG data, we took autoregressive coefficients of the AR processes to be the estimates obtained from the averaged MEG for $T=229$ when no stimulus was presented to the subject. We set the highest order to be 9 , which was selected by the minimum AIC method. In addition, we investigated cases of AR processes of orders 2 to 8 . Thus, for generating simulation data we used the following AR processes:

$$
\begin{aligned}
u_{t}= & 0.746 u_{t-1}-0.014 u_{t-2}+\xi_{t}, \\
u_{t}= & 0.764 u_{t-1}-0.368 u_{t-2}+0.467 u_{t-3}+\xi_{t}, \\
u_{t}= & 0.900 u_{t-1}-0.476 u_{t-2}+0.692 u_{t-3}-0.294 u_{t-4}+\xi_{t}, \\
u_{t}= & 1.005 u_{t-1}-0.723 u_{t-2}+0.862 u_{t-3}-0.616 u_{t-4}+0.357 u_{t-5}+\xi_{t}, \\
u_{t}= & 1.088 u_{t-1}-0.865 u_{t-2}+1.060 u_{t-3}-0.782 u_{t-4}+0.589 u_{t-5} \\
& -0.230 u_{t-6}+\xi_{t}, \\
u_{t}= & 1.117 u_{t-1}-0.940 u_{t-2}+1.161 u_{t-3}-0.918 u_{t-4}+0.700 u_{t-5} \\
& -0.370 u_{t-6}+0.129 u_{t-7}+\xi_{t}, \\
u_{t}= & 1.143 u_{t-1}-1.015 u_{t-2}+1.302 u_{t-3}-1.104 u_{t-4}+0.934 u_{t-5} \\
& -0.560 u_{t-6}+0.354 u_{t-7}-0.202 u_{t-8}+\xi_{t}, \\
u_{t}= & 1.174 u_{t-1}-1.070 u_{t-2}+1.388 u_{t-3}-1.248 u_{t-4}+1.104 u_{t-5} \\
& -0.760 u_{t-6}+0.511 u_{t-7}-0.378 u_{t-8}+0.154 u_{t-9}+\xi_{t} .
\end{aligned}
$$

Here $\xi_{t}$ is an independent and identically distributed normal random variable with mean 0 and the variance which is chosen so that $\sigma^{2}=1$. We generated 1000 replicates for $T=250$ and $\tau_{0}=100$ in each of Cases 1 to 7 . Note that $\tau_{0}=250$ when $a=0$ in Case 1 . Figure 2 shows the mean value functions in Cases 1 to 7 .

We took $L$ to be 5 in Case 3 and to be 10 in the other cases. We set $S=s_{1}=50$ and $s_{2}=250-L$. We used $z$ to be $2,3,3.5$ and 4 . We repeated estimation of the change-point 1000 times.

Tables 1 to 5 show means and MSEs of estimates of the change-point for the white noise, $\operatorname{AR}(1), \operatorname{AR}(5), \operatorname{AR}(9)$ and $\mathrm{MA}(1)$ processes. The results for the other AR processes are omitted because their relationships between MSE and $z$ are similar to those of the above 
Nonparametric Estimation and Numerical Evaluation of Time Point

Table 1. Means and MSEs of the proposed estimator for white noise

\begin{tabular}{lrrrrrrrr}
\hline \multirow{2}{*}{ Case } & \multicolumn{2}{c}{$z=2$} & \multicolumn{2}{c}{$z=3$} & \multicolumn{2}{c}{$z=3.5$} & \multicolumn{2}{c}{$z=4$} \\
\cline { 2 - 8 } & Mean & MSE $^{1 / 2}$ & Mean & MSE $^{1 / 2}$ & Mean & MSE $^{1 / 2}$ & Mean & MSE $^{1 / 2}$ \\
\hline 1 & & & & & & & & \\
$a=0$ & 98.8 & 160.9 & 203.5 & 82.3 & 231.0 & 51.7 & 243.7 & 29.2 \\
$a=1$ & 78.7 & 29.1 & 99.3 & 12.7 & 104.0 & 9.6 & 107.0 & 9.0 \\
$a=2$ & 77.4 & 29.1 & 95.1 & 12.0 & 98.4 & 7.1 & 100.3 & 3.8 \\
$a=3$ & 76.9 & 29.2 & 93.5 & 12.2 & 96.4 & 7.3 & 97.9 & 3.8 \\
2 & 77.4 & 28.7 & 93.8 & 12.2 & 97.2 & 6.3 & 98.6 & 3.4 \\
3 & 73.8 & 31.6 & 92.8 & 13.7 & 95.9 & 8.6 & 97.5 & 4.8 \\
4 & 75.7 & 32.7 & 104.2 & 15.8 & 109.8 & 14.0 & 112.8 & 14.4 \\
5 & 76.0 & 29.3 & 91.6 & 13.2 & 95.0 & 7.4 & 96.4 & 5.0 \\
6 & 78.1 & 31.5 & 107.8 & 47.9 & 127.9 & 66.5 & 151.9 & 87.3 \\
7 & 76.9 & 29.1 & 93.9 & 12.1 & 96.9 & 7.6 & 98.6 & 5.2 \\
\hline
\end{tabular}

Table 2. Means and MSEs of the proposed estimator for AR(1) process

\begin{tabular}{lrrrrrrrr}
\hline \multirow{2}{*}{ Case } & \multicolumn{2}{c}{$z=2$} & \multicolumn{2}{c}{$z=3$} & \multicolumn{2}{c}{$z=3.5$} & \multicolumn{2}{c}{$z=4$} \\
\cline { 2 - 8 } & Mean & \multicolumn{1}{c}{ MSE $^{1 / 2}$} & Mean & \multicolumn{1}{c}{ MSE $^{1 / 2}$} & Mean & MSE $^{1 / 2}$ & Mean & MSE $^{1 / 2}$ \\
\hline 1 & & & & & & & & \\
$a=0$ & 109.0 & 156.4 & 183.0 & 103.0 & 207.3 & 81.4 & 224.4 & 61.5 \\
$a=1$ & 81.4 & 30.7 & 102.7 & 22.2 & 110.0 & 22.2 & 116.4 & 24.0 \\
$a=2$ & 78.8 & 30.1 & 95.4 & 18.0 & 100.2 & 14.7 & 104.1 & 12.8 \\
$a=3$ & 77.8 & 30.0 & 92.8 & 17.4 & 96.8 & 13.5 & 99.9 & 10.3 \\
2 & 78.1 & 30.0 & 94.1 & 18.1 & 99.4 & 17.0 & 104.6 & 19.5 \\
3 & 74.3 & 32.2 & 91.8 & 18.3 & 98.1 & 18.3 & 106.1 & 28.5 \\
4 & 83.4 & 31.4 & 106.7 & 25.5 & 115.2 & 29.5 & 124.6 & 39.6 \\
5 & 77.4 & 30.1 & 95.9 & 27.2 & 106.6 & 39.3 & 121.8 & 57.3 \\
6 & 78.4 & 31.4 & 107.4 & 46.9 & 129.0 & 68.1 & 152.9 & 88.2 \\
7 & 98.0 & 13.8 & 93.3 & 17.6 & 98.0 & 13.8 & 102.0 & 14.8 \\
\hline
\end{tabular}


HEMMI

Table 3. Means and MSEs of the proposed estimator for $\mathrm{AR}(5)$ process

\begin{tabular}{lrrrrrrrr}
\hline \multirow{2}{*}{ Case } & \multicolumn{2}{c}{$z=2$} & \multicolumn{2}{c}{$z=3$} & \multicolumn{2}{c}{$z=3.5$} & \multicolumn{2}{c}{$z=4$} \\
\cline { 2 - 8 } & Mean & MSE $^{1 / 2}$ & Mean & MSE $^{1 / 2}$ & Mean & MSE $^{1 / 2}$ & Mean & MSE $^{1 / 2}$ \\
\hline 1 & & & & & & & & \\
$a=0$ & 87.8 & 170.5 & 142.9 & 133.3 & 172.5 & 111.1 & 193.5 & 93.7 \\
$a=1$ & 74.2 & 34.8 & 92.9 & 26.6 & 100.8 & 24.0 & 107.2 & 23.8 \\
$a=2$ & 72.4 & 34.4 & 87.5 & 24.3 & 93.6 & 19.8 & 97.9 & 17.0 \\
$a=3$ & 71.7 & 34.4 & 85.7 & 24.0 & 91.1 & 19.3 & 94.7 & 16.0 \\
2 & 72.0 & 34.4 & 86.8 & 24.9 & 93.2 & 21.9 & 98.4 & 22.3 \\
3 & 71.4 & 34.2 & 87.6 & 22.1 & 92.9 & 18.8 & 98.8 & 21.4 \\
4 & 75.2 & 35.1 & 95.9 & 29.5 & 105.9 & 30.8 & 114.2 & 36.2 \\
5 & 71.8 & 35.1 & 88.2 & 30.7 & 98.2 & 37.3 & 109.1 & 48.2 \\
6 & 72.7 & 36.5 & 96.5 & 44.3 & 111.8 & 55.9 & 126.3 & 68.1 \\
7 & 72.1 & 34.4 & 87.4 & 24.7 & 94.1 & 21.8 & 99.4 & 23.2 \\
\hline
\end{tabular}

Table 4. Means and MSEs of the proposed estimator for AR(9) process

\begin{tabular}{lrrrrrrrr}
\hline \multirow{2}{*}{ Case } & \multicolumn{2}{c}{$z=2$} & \multicolumn{2}{c}{$z=3$} & \multicolumn{2}{c}{$z=3.5$} & \multicolumn{2}{c}{$z=4$} \\
\cline { 2 - 8 } & Mean & \multicolumn{1}{c}{ MSE $^{1 / 2}$} & Mean & \multicolumn{1}{c}{ MSE $^{1 / 2}$} & Mean & MSE $^{1 / 2}$ & Mean & MSE $^{1 / 2}$ \\
\hline 1 & & & & & & & & \\
$a=0$ & 92.2 & 167.8 & 149.8 & 128.9 & 176.5 & 108.8 & 199.0 & 89.0 \\
$a=1$ & 75.6 & 34.3 & 94.3 & 26.3 & 102.0 & 24.6 & 109.3 & 24.2 \\
$a=2$ & 73.7 & 33.8 & 88.7 & 23.7 & 94.3 & 19.8 & 99.4 & 16.4 \\
$a=3$ & 72.9 & 33.8 & 86.7 & 23.3 & 91.6 & 19.1 & 95.9 & 15.1 \\
2 & 72.4 & 34.4 & 88.4 & 23.2 & 94.5 & 21.5 & 100.0 & 22.0 \\
3 & 73.2 & 32.8 & 88.4 & 21.6 & 94.3 & 18.3 & 100.4 & 21.2 \\
4 & 76.1 & 35.3 & 100.0 & 30.4 & 109.0 & 33.2 & 118.2 & 40.0 \\
5 & 72.9 & 34.6 & 91.2 & 33.0 & 100.6 & 39.4 & 110.9 & 48.8 \\
6 & 74.6 & 36.2 & 99.7 & 45.9 & 114.7 & 57.8 & 134.6 & 75.0 \\
7 & 73.5 & 33.5 & 88.7 & 22.0 & 93.7 & 18.2 & 97.7 & 17.6 \\
\hline
\end{tabular}


Nonparametric Estimation and Numerical Evaluation of Time Point

Table 5. Means and MSEs of the proposed estimator for MA(1) process

\begin{tabular}{lrrrrrrrr}
\hline \multirow{2}{*}{ Case } & \multicolumn{2}{c}{$z=2$} & \multicolumn{2}{c}{$z=3$} & \multicolumn{2}{c}{$z=3.5$} & \multicolumn{2}{c}{$z=4$} \\
\cline { 2 - 8 } & Mean & MSE $^{1 / 2}$ & Mean & MSE $^{1 / 2}$ & Mean & MSE $^{1 / 2}$ & Mean & MSE $^{1 / 2}$ \\
\hline 1 & & & & & & & & \\
$a=0$ & 134.0 & 137.8 & 224.3 & 61.0 & 240.3 & 36.1 & 246.4 & 21.8 \\
$a=1$ & 87.6 & 24.2 & 106.6 & 13.8 & 111.5 & 14.0 & 114.7 & 16.4 \\
$a=2$ & 85.0 & 23.8 & 99.4 & 9.3 & 102.6 & 5.7 & 104.2 & 6.1 \\
$a=3$ & 83.9 & 23.8 & 96.9 & 9.1 & 99.5 & 4.2 & 100.6 & 3.4 \\
2 & 84.1 & 23.8 & 97.7 & 9.1 & 100.4 & 4.6 & 102.0 & 5.3 \\
3 & 78.0 & 28.7 & 95.2 & 11.1 & 98.3 & 7.5 & 101.3 & 9.3 \\
4 & 90.9 & 25.2 & 111.8 & 17.6 & 116.6 & 18.4 & 119.6 & 20.7 \\
5 & 82.9 & 24.0 & 95.8 & 9.6 & 99.4 & 9.9 & 103.1 & 18.7 \\
6 & 82.5 & 24.1 & 98.6 & 21.9 & 109.7 & 38.4 & 132.8 & 67.9 \\
7 & 76.2 & 29.3 & 92.3 & 12.6 & 95.4 & 7.9 & 97.2 & 4.5 \\
\hline
\end{tabular}

five processes. We found the following tendencies. When the mean value function is linear or can be approximated by a linear function around the change-point (Cases 1, 2, 3 and 7), $z=3.5$ and $z=4$ give smaller MSEs. On the other hand, in the cases where the first derivative of the mean value function at the change-point is 0 or does not exist (Cases 4,5 and 6), the critical point $z=3.5$ is better than $z=4$. Therefore, in order to cope with various functional forms of the mean value function it is reasonable to take the critical point $z$ to be 3.5 , as far as our simulations cover.

\section{Comparisons between the proposed method and other methods by simulation}

In this section, we compare the proposed method with other nonparametric methods including Müller's method, Scariano and Watkins's method and Carlstein's method by simulation studies in various cases of mean value function. We evaluate the performance of the methods in terms of mean square error.

We took the white noise, $\operatorname{AR}(1), \operatorname{AR}(9)$ and $\mathrm{MA}(1)$ processes as $\left\{u_{t}\right\}$. Data sets for simulations are the same as those used in the previous section. For the proposed method we used $z$ to be 3.5. Müller's nonparametric method here estimates the change-point as the discontinuous point of the first derivative of the mean value function. As one-sided kernel functions we employed

$$
K_{+}(x)=36 x+96 x^{2}+60 x^{3}
$$

and

$$
K_{-}(x)=-K_{+}(-x) .
$$

We took bandwidths to be $5,10,15,20$ and 25. Table 6 shows the results for the bandwidth that gave the smallest MSE. Among Carlstein's estimators such as an arithmetic mean estimator, a Cramer-von Mises type estimator and a Kolmogorov-Smirnov type estimator we demonstrate the results for the estimator that gave the smallest MSE in Table 7. Among Scariano and Watkins's estimators including a least-squares type estimator, an area estimator and a slope difference estimator we indicate the results for the least-squares type estimator in Table 8 because this estimator gave the smallest MSE in all of the cases. In 
Table 6. Means, MSEs and MSE ratios of the Müller's estimator to the proposed estimator

\begin{tabular}{|c|c|c|c|c|c|c|c|c|}
\hline \multirow[b]{2}{*}{ Case } & \multicolumn{2}{|c|}{ White noise } & \multicolumn{2}{|c|}{$\operatorname{AR}(1)$} & \multicolumn{2}{|c|}{$\operatorname{AR}(9)$} & \multicolumn{2}{|c|}{$\mathrm{MA}(1)$} \\
\hline & Mean & $\mathrm{MSE}^{1 / 2}$ & Mean & $\mathrm{MSE}^{1 / 2}$ & Mean & $\mathrm{MSE}^{1 / 2}$ & Mean & $\mathrm{MSE}^{1 / 2}$ \\
\hline 1 & & & & & & & & \\
\hline$a=0$ & 139.1 & $\begin{array}{r}122.8 \\
(5.6)\end{array}$ & 139.8 & $\begin{array}{r}122.5 \\
(2.3)\end{array}$ & 140.2 & $\begin{array}{r}122.0 \\
(1.3)\end{array}$ & 139.8 & $\begin{array}{r}122.1 \\
(11)\end{array}$ \\
\hline$a=1$ & 135.9 & $\begin{array}{l}62.9 \\
(43)\end{array}$ & 138.5 & $\begin{array}{r}65.6 \\
(8.7)\end{array}$ & 137.6 & $\begin{array}{r}65.1 \\
(7.0)\end{array}$ & 137.4 & $\begin{array}{l}64.1 \\
(21)\end{array}$ \\
\hline$a=2$ & 128.9 & $\begin{array}{l}56.8 \\
(64)\end{array}$ & 136.1 & $\begin{array}{l}63.7 \\
(19)\end{array}$ & 134.4 & $\begin{array}{r}62.4 \\
(9.9)\end{array}$ & 133.9 & $\begin{array}{r}61.0 \\
(115)\end{array}$ \\
\hline$a=3$ & 119.9 & $\begin{array}{l}47.2 \\
(42)\end{array}$ & 133.3 & $\begin{array}{l}61.2 \\
(21)\end{array}$ & 130.6 & $\begin{array}{r}59.3 \\
(9.6)\end{array}$ & 127.9 & $\begin{array}{r}55.6 \\
(173)\end{array}$ \\
\hline 2 & 126.6 & $\begin{array}{l}49.5 \\
(61)\end{array}$ & 136.0 & $\begin{array}{l}62.4 \\
(13)\end{array}$ & 135.4 & $\begin{array}{r}59.8 \\
(7.7)\end{array}$ & 133.6 & $\begin{array}{r}60.8 \\
(174)\end{array}$ \\
\hline 3 & 108.4 & $\begin{array}{l}36.6 \\
(18)\end{array}$ & 128.6 & $\begin{array}{r}55.9 \\
(9.3)\end{array}$ & 122.3 & $\begin{array}{r}50.0 \\
(7.5)\end{array}$ & 121.3 & $\begin{array}{l}48.6 \\
(42)\end{array}$ \\
\hline 4 & 138.3 & $\begin{array}{l}64.1 \\
(21)\end{array}$ & 138.4 & $\begin{array}{r}66.0 \\
(5.0)\end{array}$ & 139.3 & $\begin{array}{r}66.1 \\
(4.0)\end{array}$ & 138.8 & $\begin{array}{l}66.0 \\
(13)\end{array}$ \\
\hline 5 & 114.1 & $\begin{array}{l}40.1 \\
(29)\end{array}$ & 130.6 & $\begin{array}{c}58.8 \\
(2.2)\end{array}$ & 128.4 & $\begin{array}{r}56.0 \\
(2.0)\end{array}$ & 129.8 & $\begin{array}{l}58.1 \\
(34)\end{array}$ \\
\hline 6 & 128.2 & $\begin{array}{r}57.8 \\
(0.76)\end{array}$ & 131.7 & $\begin{array}{r}59.4 \\
(0.76)\end{array}$ & 128.0 & $\begin{array}{r}56.4 \\
(0.95)\end{array}$ & 129.0 & $\begin{array}{r}56.4 \\
(2.2)\end{array}$ \\
\hline 7 & 134.2 & $\begin{array}{l}42.1 \\
(31) \\
\end{array}$ & 144.2 & $\begin{array}{l}57.0 \\
(17)\end{array}$ & 137.9 & $\begin{array}{r}47.3 \\
(6.8) \\
\end{array}$ & 129.5 & $\begin{array}{l}34.2 \\
(19) \\
\end{array}$ \\
\hline
\end{tabular}

MSE ratios are in parentheses.

order to see more easily which estimator is better, we calculate an MSE ratio defined as a ratio of the MSE for the alternative estimator to that for the proposed estimator. The MSE ratio in Tables 6 to 8 implies that when it is greater than one, the proposed estimator is better.

In the proposed method the MSEs for white noise and MA(1) process are smaller than those for $A R(1)$ and $A R(9)$ processes except in Case 6. As far as our simulation studies cover, the proposed method is better than Müller's and Carlstein's methods in the cases where the mean value function gradually varies from the change-point so that it is well approximated by a linear function (Cases 1,2 and 7). Scariano and Watkins's method, which is proposed for detecting the change of linear trend, works better than the proposed method when the mean value function is linear after the change-point (Case 1), but their method does not work in the other cases. On the other hand, in the cases where the mean value varies so fast (Cases 3,5 and 6) or so slowly (Case 4) around the change-point that the mean value function cannot be approximated by a linear function very well, Carlstein's method is better than the proposed method. Müller's method is inferior to the proposed method in most of the cases examined here. 
Nonparametric Estimation and Numerical Evaluation of Time Point

Table 7. Means, MSEs and MSE ratios of the Carlstein's estimator to the proposed estimator

\begin{tabular}{|c|c|c|c|c|c|c|c|c|}
\hline \multirow[b]{2}{*}{ Case } & \multicolumn{2}{|c|}{ White noise } & \multicolumn{2}{|c|}{$\operatorname{AR}(1)$} & \multicolumn{2}{|c|}{$\operatorname{AR}(9)$} & \multicolumn{2}{|c|}{$\mathrm{MA}(1)$} \\
\hline & Mean & $\mathrm{MSE}^{1 / 2}$ & Mean & $\mathrm{MSE}^{1 / 2}$ & Mean & $\mathrm{MSE}^{1 / 2}$ & Mean & $\mathrm{MSE}^{1 / 2}$ \\
\hline 1 & & & & & & & & \\
\hline$a=0$ & 131.9 & $\begin{array}{r}150.7 \\
(8.5)\end{array}$ & 127.7 & $\begin{array}{r}144.8 \\
(3.2)\end{array}$ & 128.0 & $\begin{array}{r}140.3 \\
(1.7)\end{array}$ & 130.6 & $\begin{array}{r}147.2 \\
(17)\end{array}$ \\
\hline$a=1$ & 127.6 & $\begin{array}{r}27.9 \\
(8.5)\end{array}$ & 126.7 & $\begin{array}{r}27.4 \\
(1.5)\end{array}$ & 126.4 & $\begin{array}{l}27.1 \\
(1.2)\end{array}$ & 127.4 & $\begin{array}{l}27.8 \\
(3.9)\end{array}$ \\
\hline$a=2$ & 124.8 & $\begin{array}{l}25.0 \\
(12)\end{array}$ & 124.9 & $\begin{array}{l}25.1 \\
(2.9)\end{array}$ & 125.0 & $\begin{array}{l}25.1 \\
(1.6)\end{array}$ & 124.8 & $\begin{array}{l}25.0 \\
(19)\end{array}$ \\
\hline$a=3$ & 124.9 & $\begin{array}{l}24.9 \\
(12)\end{array}$ & 124.7 & $\begin{array}{l}24.8 \\
(3.4)\end{array}$ & 124.7 & $\begin{array}{r}24.8 \\
(1.7)\end{array}$ & 124.6 & $\begin{array}{l}24.9 \\
(35)\end{array}$ \\
\hline 2 & 104.9 & $\begin{array}{r}14.4 \\
(5.2)\end{array}$ & 124.4 & $\begin{array}{r}39.0 \\
(5.3)\end{array}$ & 122.5 & $\begin{array}{r}39.6 \\
(3.4)\end{array}$ & 121.6 & $\begin{array}{l}32.9 \\
(51)\end{array}$ \\
\hline 3 & 100.1 & $\begin{array}{l}13.7 \\
(2.5)\end{array}$ & 97.2 & $\begin{array}{r}9.4 \\
(0.26)\end{array}$ & 97.1 & $\begin{array}{r}54.3 \\
(1.8)\end{array}$ & 99.7 & $\begin{array}{r}2.36 \\
(0.10)\end{array}$ \\
\hline 4 & 115.2 & $\begin{array}{l}15.7 \\
(1.3)\end{array}$ & 114.3 & $\begin{array}{r}17.9 \\
(0.37)\end{array}$ & 113.5 & $\begin{array}{r}24.6 \\
(0.55)\end{array}$ & 114.7 & $\begin{array}{r}15.6 \\
(0.72)\end{array}$ \\
\hline 5 & 100.6 & $\begin{array}{r}1.8 \\
(0.06)\end{array}$ & 99.4 & $\begin{array}{r}10.1 \\
(0.07)\end{array}$ & 97.8 & $\begin{array}{r}18.4 \\
(0.22)\end{array}$ & 100.4 & $\begin{array}{r}2.83 \\
(0.08)\end{array}$ \\
\hline 6 & 101.4 & $\begin{array}{r}9.0 \\
(0.02)\end{array}$ & 101.1 & $\begin{array}{r}8.6 \\
(0.02)\end{array}$ & 102.4 & $\begin{array}{r}16.2 \\
(0.08)\end{array}$ & 100.2 & $\begin{array}{r}2.56 \\
(0.004)\end{array}$ \\
\hline 7 & 166.9 & $\begin{array}{l}66.9 \\
(78)\end{array}$ & 169.1 & $\begin{array}{r}69.6 \\
(25)\end{array}$ & 170.1 & $\begin{array}{l}71.0 \\
(15)\end{array}$ & 166.6 & $\begin{array}{l}66.7 \\
(72) \\
\end{array}$ \\
\hline
\end{tabular}

MSE ratios are in parentheses. 
HEMMI

Table 8. Means, MSEs and MSE ratios of the Scariano-Watkins's estimator to the proposed estimator

\begin{tabular}{|c|c|c|c|c|c|c|c|c|}
\hline \multirow{2}{*}{ Case } & \multicolumn{2}{|c|}{ White noise } & \multicolumn{2}{|c|}{$\operatorname{AR}(1)$} & \multicolumn{2}{|c|}{$\mathrm{AR}(9)$} & \multicolumn{2}{|c|}{$\mathrm{MA}(1)$} \\
\hline & Mean & $\mathrm{MSE}^{1 / 2}$ & Mean & $\mathrm{MSE}^{1 / 2}$ & Mean & $\mathrm{MSE}^{1 / 2}$ & Mean & $\mathrm{MSE}^{1 / 2}$ \\
\hline 1 & & & & & & & & \\
\hline$a=0$ & 21.9 & $\begin{array}{r}236.7 \\
(21)\end{array}$ & 23.2 & $\begin{array}{r}232.7 \\
(8.2)\end{array}$ & 27.6 & $\begin{array}{r}228.4 \\
(4.4)\end{array}$ & 20.6 & $\begin{array}{r}236.7 \\
(43)\end{array}$ \\
\hline$a=1$ & 99.9 & $\begin{array}{r}9.28 \\
(0.94)\end{array}$ & 99.7 & $\begin{array}{r}11.9 \\
(0.29)\end{array}$ & 99.6 & $\begin{array}{r}14.2 \\
(0.33)\end{array}$ & 99.9 & $\begin{array}{r}9.72 \\
(0.48)\end{array}$ \\
\hline$a=2$ & 99.8 & $\begin{array}{r}4.07 \\
(0.33)\end{array}$ & 99.7 & $\begin{array}{r}5.22 \\
(0.13)\end{array}$ & 99.8 & $\begin{array}{r}6.07 \\
(0.09)\end{array}$ & 99.8 & $\begin{array}{r}4.34 \\
(0.58)\end{array}$ \\
\hline$a=3$ & 99.7 & $\begin{array}{r}2.62 \\
(0.13)\end{array}$ & 99.7 & $\begin{array}{r}3.34 \\
(0.06)\end{array}$ & 99.8 & $\begin{array}{r}3.86 \\
(0.04)\end{array}$ & 99.8 & $\begin{array}{r}2.80 \\
(0.44)\end{array}$ \\
\hline 2 & 112.9 & $\begin{array}{l}43.8 \\
(48)\end{array}$ & 108.6 & $\begin{array}{r}49.5 \\
(8.5)\end{array}$ & 117.8 & $\begin{array}{r}45.8 \\
(4.5)\end{array}$ & 108.5 & $\begin{array}{r}49.0 \\
(113)\end{array}$ \\
\hline 3 & 19.9 & $\begin{array}{r}96.6 \\
(126)\end{array}$ & 21.0 & $\begin{array}{l}90.8 \\
(25)\end{array}$ & 26.4 & $\begin{array}{l}87.3 \\
(23)\end{array}$ & 17.7 & $\begin{array}{r}95.7 \\
(164)\end{array}$ \\
\hline 4 & 34.0 & $\begin{array}{l}81.2 \\
(34)\end{array}$ & 32.8 & $\begin{array}{r}81.0 \\
(7.5)\end{array}$ & 37.4 & $\begin{array}{r}78.9 \\
(5.6)\end{array}$ & 32.5 & $\begin{array}{l}82.0 \\
(20)\end{array}$ \\
\hline 5 & 66.1 & $\begin{array}{r}86.1 \\
(134)\end{array}$ & 65.6 & $\begin{array}{r}84.0 \\
(4.6)\end{array}$ & 76.6 & $\begin{array}{r}79.8 \\
(4.1)\end{array}$ & 60.1 & $\begin{array}{l}86.7 \\
(76)\end{array}$ \\
\hline 6 & 24.7 & $\begin{array}{r}91.6 \\
(1.9)\end{array}$ & 24.2 & $\begin{array}{r}92.2 \\
(1.8)\end{array}$ & 33.6 & $\begin{array}{c}89.3 \\
(2.4)\end{array}$ & 18.4 & $\begin{array}{r}96.0 \\
(6.3)\end{array}$ \\
\hline 7 & 144.8 & $\begin{array}{l}45.3 \\
(36)\end{array}$ & 144.8 & $\begin{array}{l}45.3 \\
(11)\end{array}$ & 143.7 & $\begin{array}{r}45.4 \\
(6.2)\end{array}$ & 145.2 & $\begin{array}{l}45.3 \\
(33)\end{array}$ \\
\hline
\end{tabular}

MSE ratios are in parentheses. 


\section{Application to MEG data}

MEG data for this analysis were a part of the data recorded by Yoneda et al. (1995). A flash light was presented to the right hemiretina of the right eye of the subject using a light-proof stimulating goggle. The MEG was measured with a sensor above the right side of the occipital lobe. The period of recording consisted of a 20 -ms pre-stimulus period and a 200 -ms post-stimulus period. Sampling rate was $1041.7 \mathrm{~Hz}$. In other words, the number of observed time points was 229 and the stimulus was presented to the subject at time point 22. The averaged MEG to be analyzed was obtained from 500 repetitions of stimulation (Table 9 and Figure 3). It is difficult to see the change-point in the plot precisely.

For applying the proposed method, we estimated $\left\{\gamma_{h}\right\}$ from $\left\{Y_{t}\right\}, t=1, \ldots, 22$. To fit a linear function we chose $L=10$ from the sample path in Figure 3. The critical point $z$ was 3.5. We searched for the change-point from $s_{1}=22$ to $s_{2}=219$. The estimate of the change-point by the proposed method is 50 , that is, $48 \mathrm{~ms}$. This implies that the CEP appears $28 \mathrm{~ms}$ after the stimulation. Yoneda et al. found that the early component of the visual evoked potential in the MEG, which was obtained from 4000 repetitions, has a peak between 41 and $44 \mathrm{~ms}$. Our estimate does not contradict their result. Therefore, the proposed method seems to be applicable to estimating the time point of the occurrence of the CEP from fewer repetitions.

In addition, we tried the smaller values of the critical point, $z=2$ and $z=3$. They gave us the estimates $22(20 \mathrm{~ms})$ and $23(22 \mathrm{~ms})$ for $z=2$ and 3 , respectively. Both estimates are not convincing from the physiological point of view because they imply that the information of light stimulus is transferred too fast.

\section{Conclusion}

When the functional form of mean value function that gradually varies is not known, the proposed method is suitable for estimating the change-point at which a stationary process changes to a mean-varying nonstationary process. Consequently, the proposed method is useful for estimating the time point at which the CEP occurs from MEG data.

\section{ACKNOWLEDGMENTS}

The author would like to thank Professor Mituaki Huzii, Tokyo Institute of Technology, for his helpful comments, and Professor Morihiro Sugishita, University of Tokyo, for providing the MEG data. Appreciation is also extended to the referee for his useful comments. 
HEMMI

Table 9. The MEG data.

\begin{tabular}{rrrrrrrr}
\hline $1-30$ & $31-60$ & $61-90$ & $91-120$ & $121-150$ & $151-180$ & $181-210$ & $211-229$ \\
\hline-18.32 & -4.35 & -38.62 & -76.24 & -6.89 & -39.79 & -19.32 & -63.75 \\
-26.31 & 9.64 & -21.82 & -70.44 & 11.88 & -29.55 & 6.92 & -60.08 \\
-19.45 & 8.00 & -29.73 & -71.06 & 31.72 & -36.40 & -5.93 & -54.09 \\
-4.13 & 1.47 & -38.22 & -71.53 & 17.46 & -34.12 & -3.52 & -60.97 \\
-11.62 & 7.73 & -29.88 & -62.01 & 11.86 & -48.27 & 22.07 & -69.67 \\
-21.08 & 1.11 & -31.70 & -54.77 & 14.60 & -57.53 & 15.65 & -74.54 \\
-18.45 & -4.92 & -40.75 & -52.95 & 15.35 & -40.29 & 12.50 & -87.75 \\
-15.26 & 6.28 & -43.29 & -55.22 & 24.63 & -41.30 & 25.31 & -87.13 \\
-20.89 & 6.82 & -42.31 & -48.16 & 11.19 & -50.24 & 29.07 & -75.46 \\
-18.55 & 1.89 & -41.24 & -36.09 & 1.39 & -51.05 & 24.32 & -81.56 \\
-4.35 & -5.34 & -45.32 & -30.94 & 6.46 & -55.21 & 9.01 & -79.69 \\
-4.99 & -12.30 & -51.24 & -24.87 & -12.82 & -48.51 & 7.79 & -67.76 \\
-13.57 & -7.44 & -52.28 & -22.23 & -20.26 & -51.48 & 24.84 & -74.65 \\
-21.37 & 1.46 & -59.38 & -17.73 & -6.16 & -62.09 & 26.12 & -78.59 \\
-22.69 & 2.25 & -65.03 & -11.17 & -8.42 & -51.13 & 10.04 & -73.43 \\
-6.11 & -4.93 & -55.35 & -19.45 & -10.60 & -48.20 & 0.56 & -69.71 \\
-2.10 & -6.41 & -58.80 & -19.06 & -23.74 & -51.36 & 1.13 & -61.78 \\
-10.98 & 0.14 & -78.55 & 3.01 & -39.01 & -46.61 & -9.63 & -63.63 \\
-7.37 & -4.63 & -80.33 & 16.33 & -26.04 & -51.42 & -16.85 & -69.29 \\
-1.16 & -13.27 & -67.35 & 11.44 & -22.51 & -47.82 & -3.48 & \\
-0.66 & -9.76 & -66.84 & 5.31 & -39.07 & -39.63 & -4.09 & \\
-12.73 & -8.75 & -76.30 & 10.59 & -36.26 & -34.07 & -23.26 & \\
-17.10 & -15.62 & -69.74 & 7.92 & -25.13 & -20.60 & -33.26 & \\
-5.86 & -16.26 & -70.67 & -4.50 & -35.88 & -29.31 & -29.59 & \\
-7.89 & -10.01 & -94.56 & 9.19 & -42.72 & -41.57 & -30.77 & \\
-8.26 & -15.60 & -83.05 & 32.61 & -34.28 & -28.90 & -43.84 & \\
-0.54 & -34.86 & -56.44 & 21.99 & -35.02 & -28.91 & -46.52 & \\
-4.25 & -34.20 & -66.95 & 10.48 & -35.19 & -29.59 & -46.20 & \\
2.45 & -25.17 & -74.74 & 17.98 & -42.04 & -20.27 & -58.41 & \\
3.79 & -38.75 & -73.47 & 8.29 & -54.76 & -30.42 & -64.39 & \\
\hline & -1.5 & 5 & &
\end{tabular}

The light stimulus is presented at 22 . 


\section{REFERENCES}

Carlstein, E. (1988). Nonparametric change-point estimation, Ann. Statist., 16, 188-197.

Carlstein, E. and Lele, S. (1994). Nonparametric change-point estimation for data from an ergodic sequence, Theor. Probab. Appl., 38, 726-733.

Chu, C.K. (1994). Estimation of change-points in a nonparametric regression function through kernel density estimation, Commun. Statist.-Theory Meth., 23, 3037-3062.

Glaser, E.M. and Ruchkin, D.S. (1976). Principles of Neurological Signal Analysis. New York: Academic Press.

Hinkley, D.V. (1969). Inference about the intersection in two-phase regression, Biometrika, 56, 495-504.

Kim, H.J. and Siegmund, D. (1989). The likelihood ratio test for a change-point in simple linear regression, Biometrika, 76, 409-423.

Lee, T. (1993). Estimating coefficients of two-phase linear regression model with autocorrelated errors, Statist. Probab. Lett., 18, 113-120.

Müller, H.G. (1992). Change-points in nonparametric regression analysis, Ann. Statist., 20, 737-761.

Quandt, R.E. (1958). The estimation of the parameters of a linear regression system obeying two separate regimes, J. Amer. Statist. Assoc., 53, 873-880.

Scariano, S.M. and Watkins, T.A. (1988). An algorithm for computing nonparametric estimators of change-points, Commun. Statist.-Simul. Comput., 17, 1511-1532.

Yoneda, K., Sekimoto, S., Yumoto, M. and Sugishita, M. (1995). The early component of the visual evoked magnetic field, Neuro Report, 6, 797-800.

(Received September 1996; Revised December 1996) 


$$
p=0.05, s=20
$$

$$
p=0.05, s=50
$$
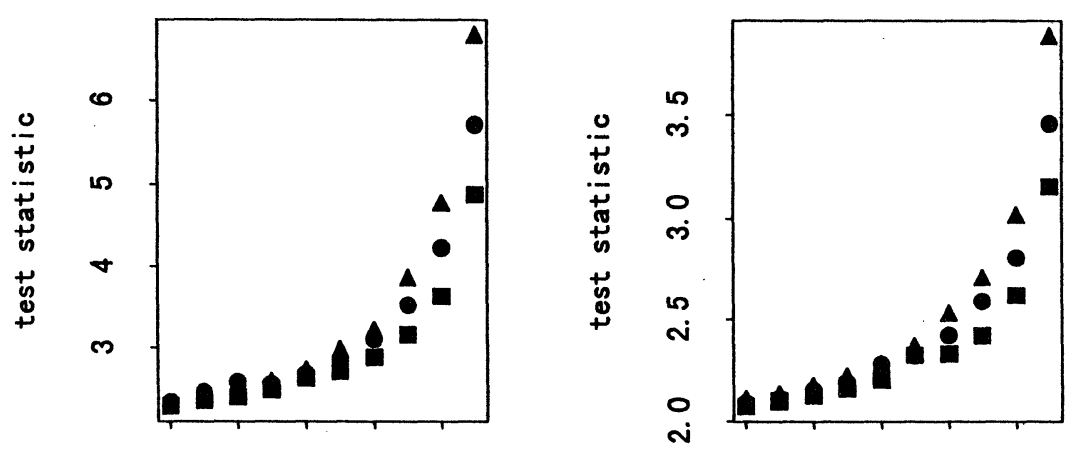

0.0

0.4

0.8

0.0

0.4

0.8

autocorrelation at lag 1 autocorrelation at lag 1

$p=0.05, S=100$

$p=0.05, s=200$

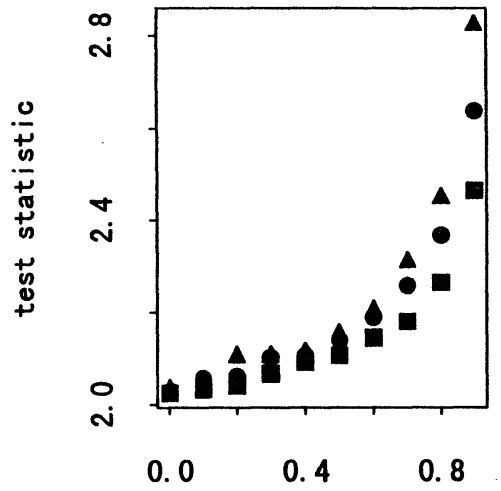

autocorrelation at lag 1

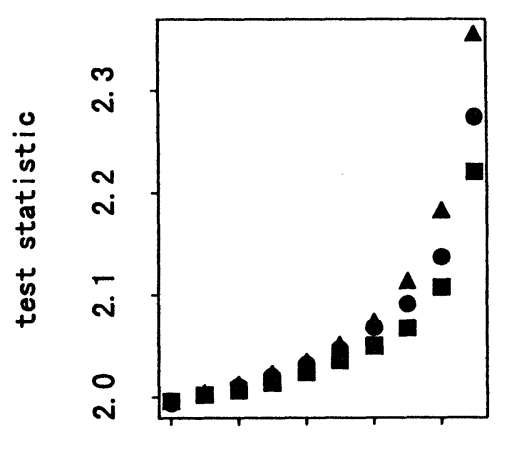

$\begin{array}{lll}0.0 & 0.4 & 0.8\end{array}$ autocorrelation at lag 1

Figure 1. Plots of test statistic against autocorrelation coefficient at lag 1 by significance level $p$, interval length $L$ for fitting a linear function, and interval length $S$ for estimating $\left\{\gamma_{h}\right\}$. Square indicates $L=5$, circle $L=10$ and triangle $L=20$. 
Nonparametric Estimation and Numerical Evaluation of Time Point
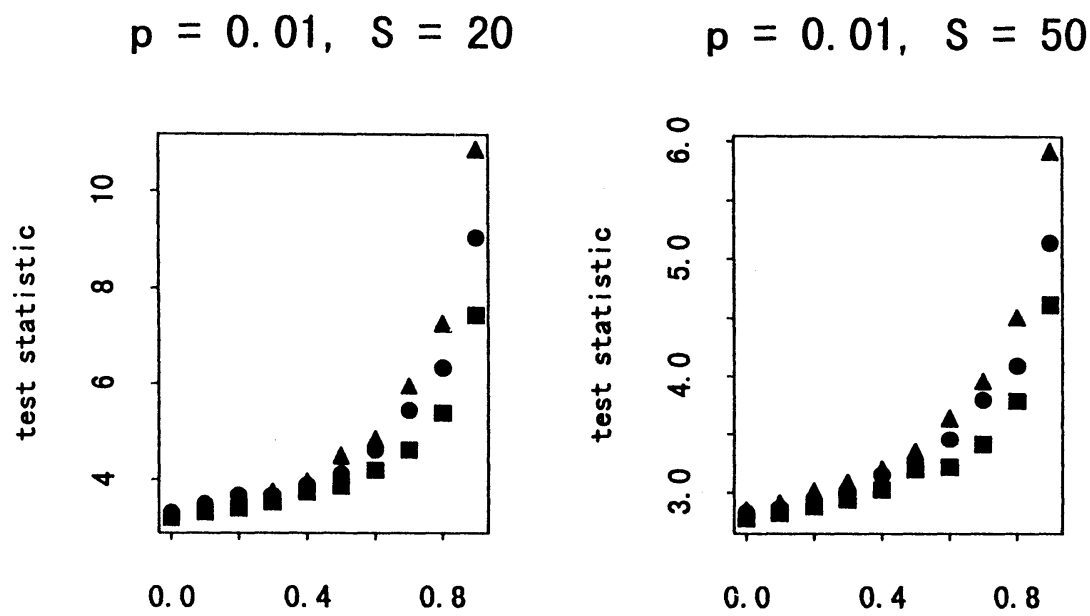

autocorrelation at $\operatorname{lag} 1$ autocorrelation at lag 1

$p=0.01, s=100$

$p=0.01, s=200$
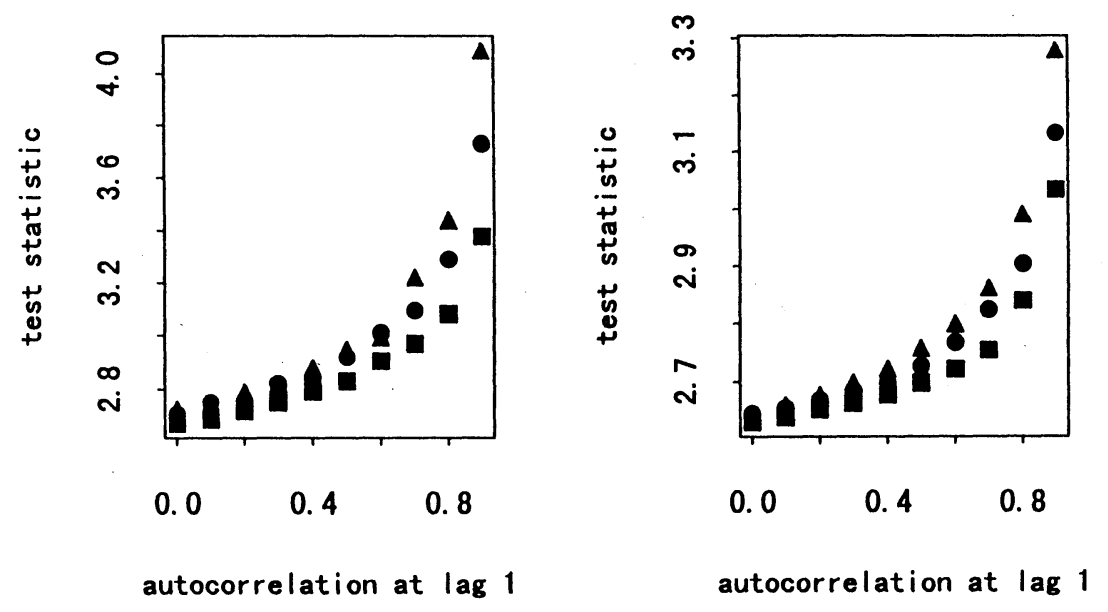

Figure 1 (continued) 


$$
p=0.005, s=20
$$

$$
p=0.005, s=50
$$
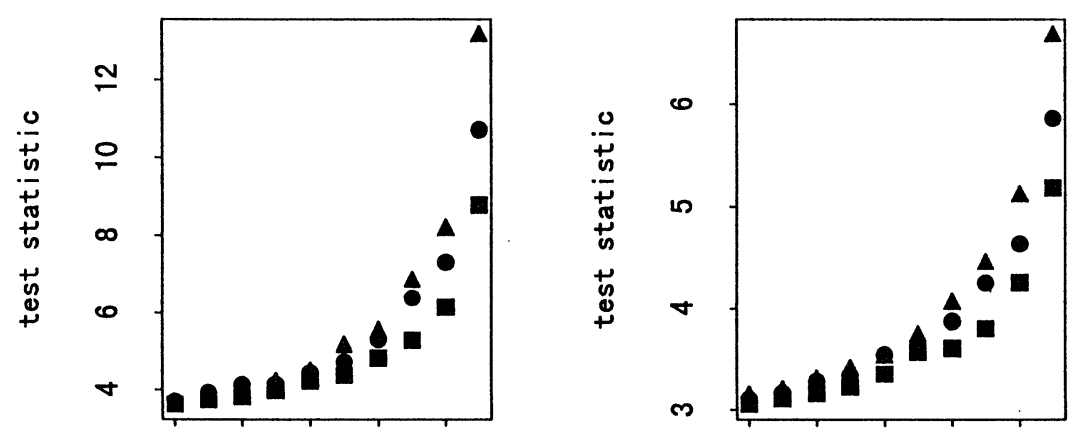
0. 0
0.4
0. 8

0.0

0. 4

0. 8

autocorrelation at lag 1 autocorrelation at lag 1

$p=0.005, s=100$

$p=0.005, \quad s=200$
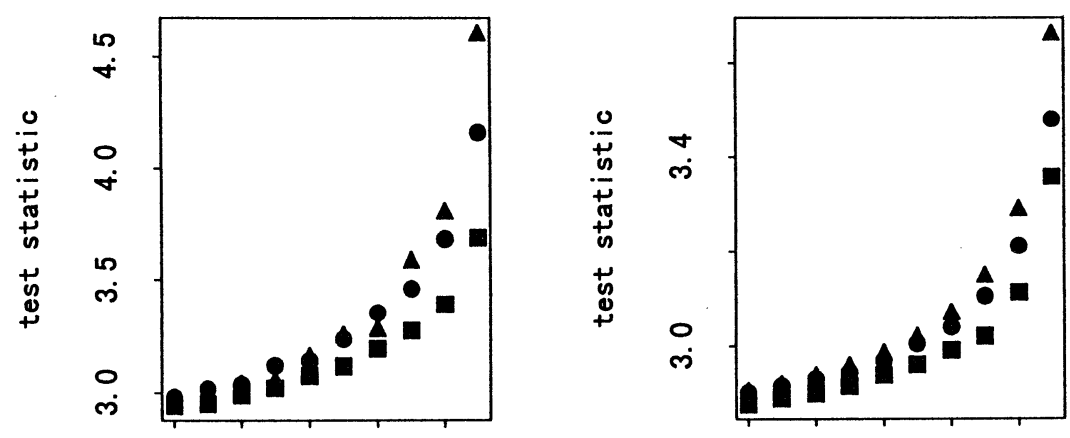
0.0
0.4
0.8

0.0

0.4

0.8

autocorrelation at lag 1 autocorrelation at lag 1

Figure 1 (continued) 
$p=0.001, s=20$

$$
p=0.001, s=50
$$
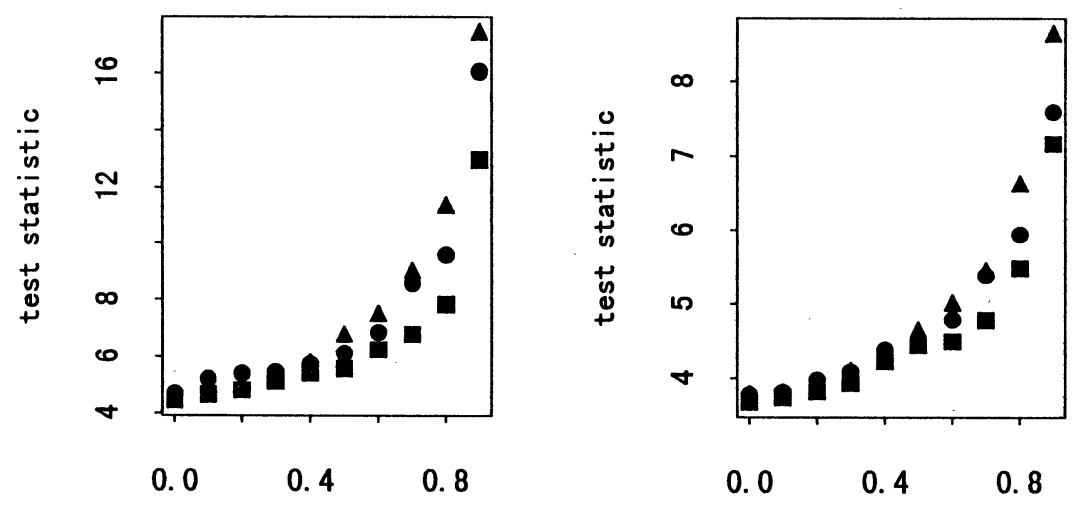

autocorrelation at lag 1 autocorrelation at lag 1

$$
p=0.001, s=100
$$

$p=0.001, S=200$

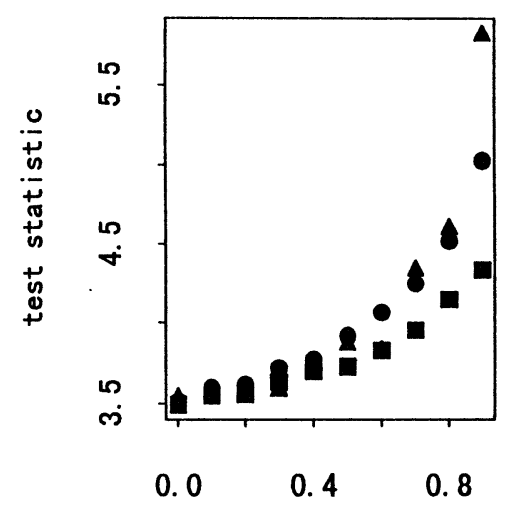

autocorrelation at $\operatorname{lag} 1$

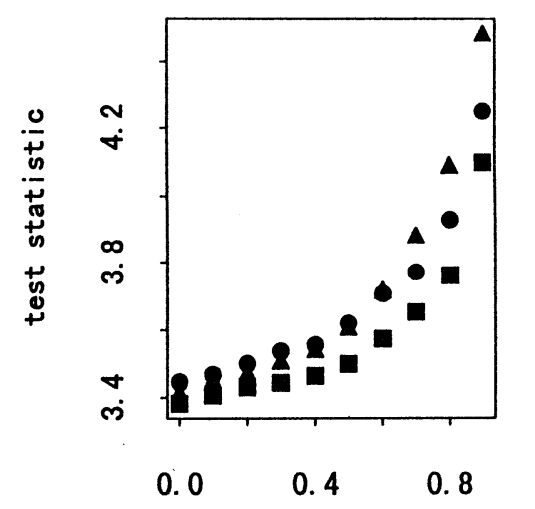

autocorrelation at $\operatorname{lag} 1$

Figure 1 (continued) 
HEMMI
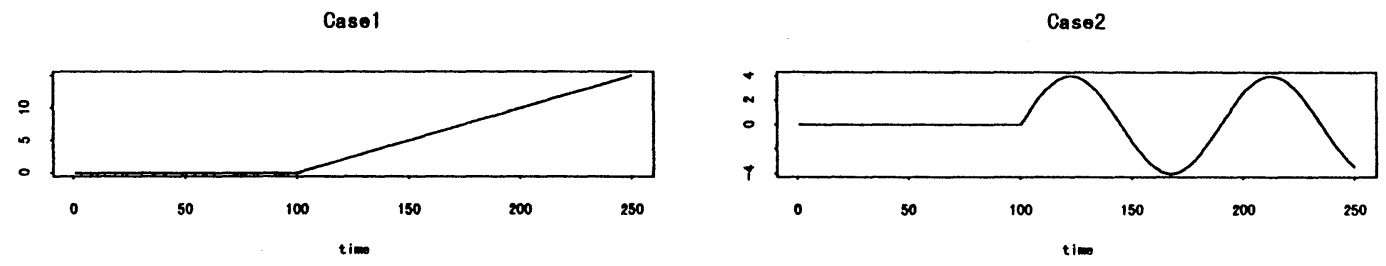

Case3
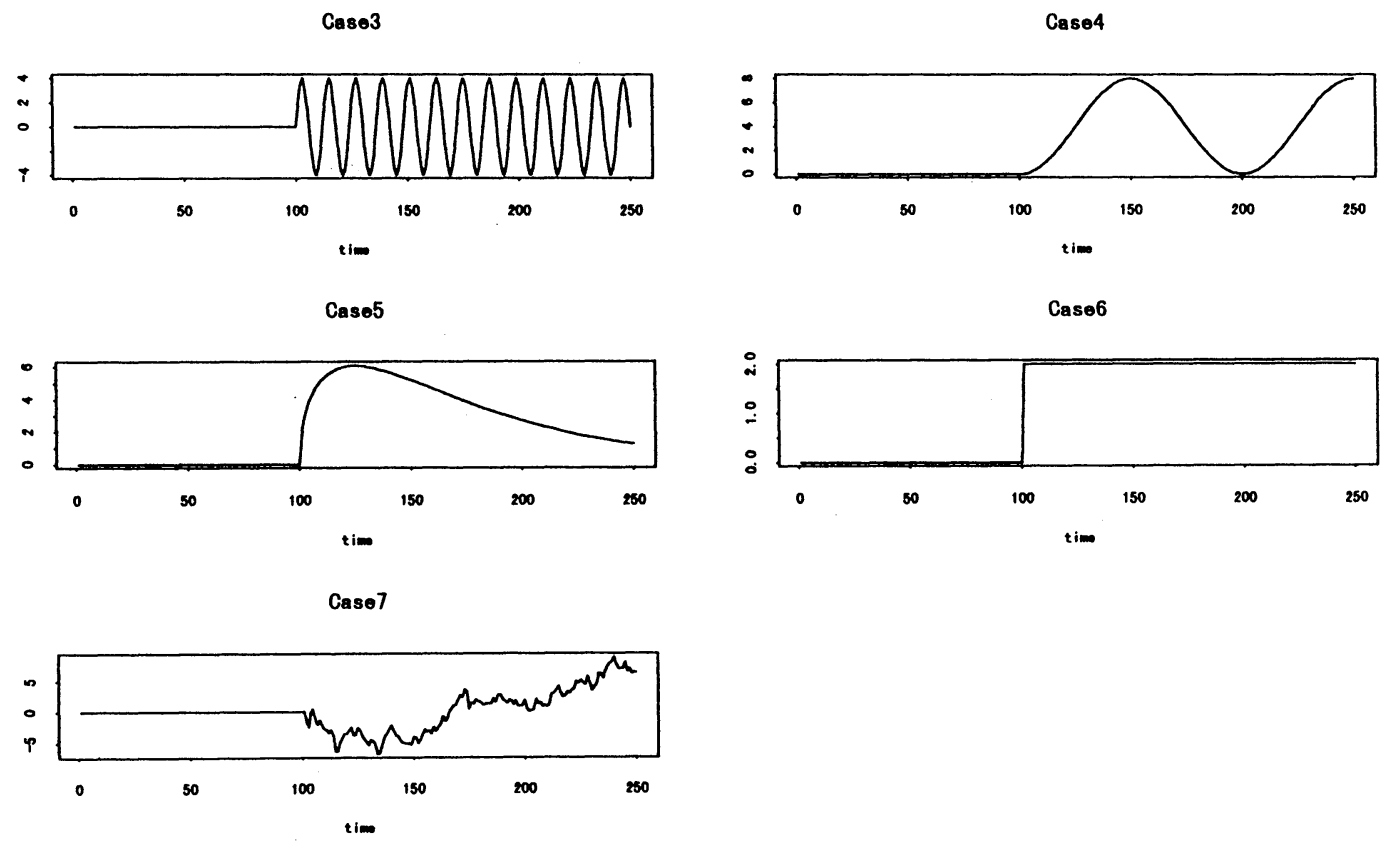

Figure 2. Mean value functions in Cases 1 to 7 . 
Nonparametric Estimation and Numerical Evaluation of Time Point

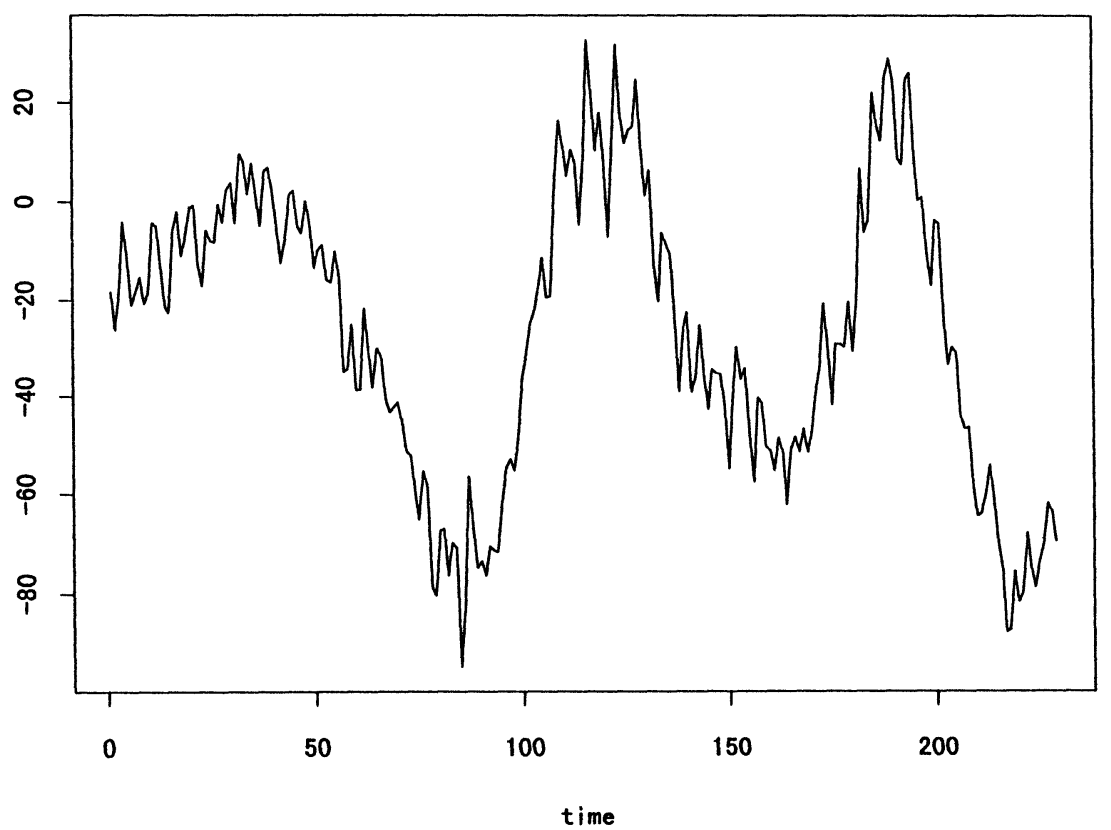

Figure 3. Averaged MEG obtained from 500 repetitions. 